\title{
PERFORMANCE RATING METHOD OF THERMOSYPHON SOLAR WATER HEATERS
}

\author{
B. J. HUANG \\ Department of Mechanical Engineering, National Taiwan University, Taipei, 10764, Taiwan
}

\begin{abstract}
A rating method for the thermal performance of thermosyphon solar water heaters was developed. Except that the outdoor test procedure still follows the Taiwan Standard CNS B7277, a system characteristic efficiency $\eta_{s}^{*}$ which is defined as the $\alpha_{o}$ value corrected at $M / A_{c}=75 \mathrm{~kg} / \mathrm{m}^{2}$, was derived so that $\eta_{s}^{*}$ is independent of the $M / A_{c}$ ratio. Here, $\eta_{s}^{*}$ can be evaluated by linear regression analysis of the test data. It is found from a series of tests for 31 systems that $\eta_{s}^{*}$ is independent of $M / A_{c}$ indeed, and thus can be used to rate the thermal performance of different thermosyphon solar water heaters during the energy-collecting period. The cooling loss during the no-radiation period is rated by the system cooling time constant $\tau_{c}$. The present rating method associated with the Taiwan Standard CNS B7277 has been implemented for more than three years and is accepted by the Taiwan solar industry.
\end{abstract}

\section{INTRODUCTION}

Commercialization of thermosyphon solar water heaters is very successful in Taiwan. The number of units installed is around 25,000 per year, mostly for domestic applications. The market will be expanded several folds in the near future. The rapid growth of the solar market is mainly a result of the subsidy program provided by the Energy Commission, Ministry of Economic Affairs, Taiwan, which was started in 1986 and ended at the end of 1991. To improve the quality, the subsidy program requires that all the qualified products should pass a performance test with results exceeding certain criteria. Therefore, a method for the performance rating of the different solar water heaters on a commonly trusted basis was required.

Through a series of research programs, the Taiwanese Testing Standard (CNS B7277) was established in 1989 for the thermal performance test of thermosyphon solar water heaters [1,2]. This standard has been implemented in an expert system, which was developed and has been continuously running for about three years since early 1989 (see[1]). More than 30 commercial solar water heaters have been tested so far and the results are collected and analyzed. The semiempirical efficiency model: $\eta_{s}=\alpha_{o}-U_{s}\left(T_{i}-\bar{T}_{a}\right) / H_{l}$, which was derived to correlate the daily efficiency test results[1], was carefully examined and no serious defect has yet been found.

It has been shown that the parameters $\alpha_{o}$ and $U_{s}$, defined in the above equation, can be used to rate the thermal performance of thermosyphon solar water heaters during energy-collecting periods[1]. Above, $\alpha_{o}$ is related to the solar energy absorption efficiency of the collector; while $U_{s}$ stands for the capability of the system heat loss to ambient during the energy-collecting periods. However, two problems may arise by this rating method.

First, the testing result of $U_{s}$ may have a larger uncertainty, sometimes $> \pm 20 \%$, which is caused by the scattering of the field test data due to inevitable dis- turbances of the testing environment[1]. Therefore, the performance rating based on the results of $U_{s}$ may be deviated and cause serious controversy in obtaining the subsidy. Second, $\alpha_{o}$ and $U_{s}$ can be varied by changing the system designs with various $M / A_{c}$ ratios, so that the rating may become unfair. For example, filling more water in the tank during the test will increase the $M / A_{c}$ ratio as well as the testing result on $\alpha_{o}$. This can easily be done during the test for thermosyphon solar water heaters of the nonpressurized type (with a float valve in the tank to control the makeup water flow to the tank). A larger $M / A_{c}$ value can also be achieved by designing a larger tank size in order to pass the performance test, though the hot water will be supplied at a lower temperature which may not meet the load requirement.

Therefore, it is realized that the performance rating based purely on the values of $\alpha_{o}$ and $U_{s}$ may be unfair. To overcome this problem, we have to seek a rating method that is independent of the $M / A_{c}$ ratio.

In practice, the daily initial temperature of the thermosyphon systems, $T_{i}$, is relatively low since the hot water collected during daytime is completely used at night and cold make-up water is refilled again. Therefore, the performance rating using $U_{s}$ is not always necessary since $T_{i}$ approaches $\bar{T}_{a}$, i.e., $\left(T_{i}-\bar{T}_{a}\right) / H_{i}$ $\approx 0$. This means that the rating method can be simplified. Therefore, we solely select the value of $\alpha_{o}$ for the performance rating of different thermosyphon solar water heaters during energy-collecting periods, but redefine it so that it will not depend on the $M / A_{c}$ ratio. The modified $\alpha_{o}$ (called system characteristic efficiency denoted by $\eta_{s}^{*}$ ) will then be used in the rating.

The system cooling loss during the no-radiation period (particularly at night) basically includes the insulation loss and the reverseflow loss. The cooling loss test can be performed to determine the cooling time constant $\tau_{c}$ by the testing method presented in Huang and Du's article[1]. The effect of reverse flow can also be analyzed by comparing the cooling time constant, $\tau_{c}$, of the individual tank loss and the system loss[1]. 


\section{DERIVATION OF CHARACTERISTIC SYSTEM EFFICIENCY}

We start with the daily system efficiency model derived in the previous study[1]:

$$
\eta_{s}=\alpha_{o}-U_{s} \frac{T_{i}-\bar{T}_{a}}{H_{t}}
$$

where

$$
\alpha_{o} \equiv \alpha_{e}-\frac{\beta}{\left(M / A_{c}\right)} ; \quad \beta \equiv \frac{b U_{s}}{2} .
$$

In eqn (2), $\alpha_{e}$ is the average solar absorption coefficient; $b$ is the proportional constant between $T_{f}-T_{i}$ and $H_{t} A_{c} / M$, according to Kubler et al.[3] and Adnot et al. [4]. That is,

$$
T_{f}-T_{i}=b \frac{H_{t} A_{c}}{M}
$$

Here, $H_{t}$ is the daily total solar irradiation upon the collector slope:

$$
H_{t}=\int_{t_{i}}^{t_{f}} I_{T} d t
$$

where $t_{i}$ and $t_{f}$ are the initial and final time, respectively, during energy collecting period at each test day.

The system efficiency model, eqn (1), has been verified experimentally well in the previous study[1]. The parameter $\alpha_{o}$ can be interpreted as the daily system efficiency if the initial water temperature $T_{i}$ is as cold as the mean ambient temperature $\bar{T}_{a}$. It can also be seen from eqn (2) that the parameter $\alpha_{o}$ is dependent on the $M / A_{c}$ ratio. The larger the water mass in the tank, the higher the value of $\alpha_{o}$. Thus, the higher value of $\alpha_{o}$ can be easily obtained by filling more water in the tank during the test. Therefore, a correction of the parameter $\alpha_{o}$ from an arbitrary $M / A_{c}$ value to a fixed $M / A_{c}$ value is necessary in the performance rating of different thermosyphon solar water heaters.

The system parameters $\alpha_{o}$ and $U_{s}$ are determined from the linear regression analysis of eqn (1) by using the measured system efficiency $\eta_{s}$ (the dependent variable) and $\left(T_{i}-\bar{T}_{a}\right) / H_{t}$ (the independent variable). The constant $b$ defined in the second part of eqn (2) is determined separately by linear regression analysis to the model eqn (3) by using the measured $T_{f}-T_{i}$ (the dependent variable) and $H_{t} A_{c} / M$ (the independent variable). The coefficient $\beta$ can then be evaluated by using the second part of eqn (2) and $\alpha_{e}$ can be found from the first part of eqn (2):

$$
\alpha_{e}=\alpha_{o}+\frac{\beta}{M / A_{c}}
$$

With known $\beta$ and $\alpha_{e}$, we can extrapolate the test results of $\alpha_{o}$ to the point with a fixed $M / A_{c}$ value. Here,
$M / A_{\mathrm{c}}=75 \mathrm{~kg} / \mathrm{m}^{2}$ was chosen as the criterion and the corrected $\alpha_{o}$, denoted $\left.\alpha_{o}\right|_{75}$ or $\eta_{s}^{*}$ becomes:

$$
\eta_{s}^{*}=\left.\alpha_{o}\right|_{75}=\alpha_{e}-\frac{\beta}{75} .
$$

The corrected $\alpha_{o}$, denoted $\eta_{s}^{*}$, is the system characteristic efficiency which can be used as the criterion for the performance rating of different thermosyphon solar water heaters in the energy absorption phase.

Substituting eqn (5) into eqn (6), we obtain:

$$
\eta_{s}^{*}=\alpha_{o}+\frac{\beta}{M / A_{c}}-\frac{\beta}{75}=\alpha_{o}+\left[\frac{1}{\left(M / A_{c}\right)}-\frac{1}{75}\right] \beta \text {. }
$$

Equation (7) can be written in the form

$$
\eta_{s}^{*}=C_{F} \alpha_{o}
$$

where $C_{F}$ is the correction factor which is defined as

$$
C_{F}=1+\left[\frac{1}{\left(M / A_{c}\right)}-\frac{1}{75}\right] \frac{\beta}{\alpha_{o}} .
$$

Since $\beta=b U_{s} / 2, C_{F}$ can be evaluated when the parameters $b, U_{s}$, and $\alpha_{o}$ have been determined. The above derivation of the system characteristic efficiency $\eta_{s}^{*}$ is basically semiempirical and thus needs experimental verifications.

\section{VERIFICATION BY FIELD TESTS}

An experiment with seven thermosyphon solar water heaters, i.e., Systems A, B, C, D, E, F, and G used by Huang and Du[1], were carried out in the present study. The outdoor tests were performed automatically by the expert system developed previously[1]. The testing procedure follows Standard CNS B7277[2] with the following operating conditions:

1. Period of day for daily efficiency test: nine hours with symmetry to the solar noon time.

2. $H_{t} \geq 7 \mathrm{MJ} / \mathrm{m}^{2}$ day for each test day.

3. Daily-mean wind speed during tests $\bar{v}_{w} \leq 3 \mathrm{~m} / \mathrm{s}$ for each test day.

4. $-0.5 \leq \frac{T_{i}-\bar{T}_{a}}{H_{t}} \leq 2.0^{\circ} \mathrm{C} \mathrm{m}{ }^{2}$ day/MJ

5. At least ten test points, which satisfy the above testing conditions, have to be taken.

The parameters $\alpha_{o}$ and $U_{s}$, obtained from linear regression analysis of the test data using eqn (1) are listed in Table 1. The correlation coefficients of eqn (1) are well shown and the system efficiency model was validated. The proportional constant, $b$, the correction factor, $C_{F}$, and the characteristic system efficiency $\eta_{s}^{*}$ were further calculated. The results are listed in Table 2. The correlation coefficients presented in Table 2 are very close to 1.0 and thus eqn (3) is shown to be valid.

To further verify the suitability of the correction method for the rating of thermosyphon solar water heaters, a large number of field test data to check 
Table 1. Fitting of test results for the system efficiency model, eqn (1)

\begin{tabular}{ccccc}
\hline System & $\begin{array}{c}M / A_{c} \\
\left(\mathrm{~kg} / \mathrm{m}^{2}\right)\end{array}$ & $\alpha_{o}$ & $\begin{array}{c}U_{s} \\
\left(\mathrm{MJ} / \mathrm{m}^{2}{ }^{\circ} \mathrm{C} \text { day }\right)\end{array}$ & $\begin{array}{c}\text { Correlation coefficient } \\
\text { of eqn }(1)\end{array}$ \\
\hline $\mathrm{A}$ & 73.4 & 0.397 & 0.174 & -0.944 \\
$\mathrm{~B}$ & 78.6 & 0.517 & 0.147 & -0.986 \\
$\mathrm{C}$ & 74.5 & 0.592 & 0.162 & -0.944 \\
$\mathrm{D}$ & 81.8 & 0.506 & 0.114 & -0.895 \\
$\mathrm{E}$ & 67.8 & 0.487 & 0.129 & -0.883 \\
$\mathrm{~F}$ & 71.8 & 0.507 & 0.190 & -0.943 \\
$\mathrm{G}$ & 77.9 & 0.566 & 0.170 & -0.955 \\
\hline
\end{tabular}

whether $\eta_{s}^{*}$ is independent of $M / A_{c}$, is required. Thirtyone commercially available solar water heaters have been tested and analyzed. The results are summarized in Table 3. Figure 1 shows that $\alpha_{o}$ increases with increasing $M / A_{c}$ ratio, as was expected by eqn (2). The effect of $M / A_{c}$ is not very clear for $U_{s}$, as shown in Fig. 2. Figure 3 shows that the system characteristic efficiency $\eta_{s}^{*}$ is independent of the $M / A_{c}$ ratio indeed. This indicates that the performance rating of solar water heaters by using the $\eta_{s}^{*}$ value will not be biased by the variation of the $M / A_{c}$ ratio, and thus can be commonly trusted.

Table 3 also presents the test results of the cooling time constant $\tau_{c}$, which can be used to rate the performance during no-radiation or cooling-loss periods. Here, $\tau_{c}$ is defined as

$$
\tau_{c}=\frac{M C_{p}}{(U A)_{L}}
$$

which is derived by a first-order system cooling model[1]:

$$
M C_{p} \frac{d T_{t}(t)}{d t}=-(U A)_{L}\left[T(t)-\bar{T}_{a}\right]
$$

where $T_{\mathrm{t}}$ is the bulk temperature of water in the tank; $(U A)_{L}$ is the total heat loss coefficient of the system (including tank, collector, and connecting pipes); $\bar{T}_{a}$ is the mean ambient temperature during the no-radiation test period. Therefore, $\tau_{c}$ represents the time at which the difference between the hot water temperature in the tank and the mean ambient temperature drops to $36.8 \%$ of its initial temperature difference, i.e., $T_{t}(0)$
$-\bar{T}_{a}$. Table 3 shows that $\tau_{c}$, for most solar water heaters, exceeds 2 days.

A criterion of $\eta_{s}^{*} \geq 0.5$ during energy-collecting periods has been adopted by the Taiwan Government in early 1989 as a necessary condition for the acceptance of the subsidy program. By this criterion, 7 out of 31 systems tested in the present study were not allowed to accept subsidy. In addition to the performance criterion during energy-collecting periods, $\tau_{c} \geq 2.0$ days will be suggested in the future as an additional criterion for performance during no-radiation or cooling-loss periods in order to make the rating more complete. If both the criteria of $\eta_{s}^{*}$ and $\tau_{c}$ were obeyed, then eight systems will not pass the test.

\section{DISCUSSION AND CONCLUSIONS}

In the present study, a method of performance rating for different solar water heaters was derived. The outdoor test procedure basically follows the Taiwanese Standard B7277[1,2]. In addition, a system characteristic efficiency, $\eta_{s}^{*}$, which is defined as the $\alpha_{o}$ value corrected at $M / A_{c}=75 \mathrm{~kg} / \mathrm{m}^{2}$, was further derived, so that $\eta_{s}^{*}$ is independent of $M / A_{c}$. Then, $\eta_{s}^{*}$ can be evaluated by linear regression analysis of test data using eqn (3) in conjunction with eqns (2) and (7). From the tests of 31 solar water heaters, it was found that $\eta_{s}^{*}$ is indeed independent of $M / A_{c}$ and thus can be used to rate the thermal performance of different thermosyphon solar water heaters during energy-collecting periods. The present rating method has been used for more than three years during the subsidy program, and is now widely accepted by Taiwanese solar industry.

A criterion of $\eta_{s}^{*} \geq 0.5$ during energy-collecting periods has been adopted by the Taiwan Government in

Table 2. Fitting of test results for eqn (3)

\begin{tabular}{ccccccc}
\hline System & $\begin{array}{c}M / A_{c} \\
\left(\mathrm{~kg} / \mathrm{m}^{2}\right)\end{array}$ & $b / C_{p}$ & $\begin{array}{c}\text { Correlation coefficient } \\
\text { of eqn (3) }\end{array}$ & $\alpha_{o}$ & \multicolumn{3}{c}{ Correction factor } \\
\hline A & 73.4 & 0.342 & 0.978 & 0.397 & $C_{F}$ & $\eta_{s}^{*}$ \\
B & 78.6 & 0.517 & 0.969 & 0.517 & 0.991 & 0.399 \\
C & 74.5 & 0.504 & 0.938 & 0.592 & 1.001 & 0.512 \\
D & 81.8 & 0.506 & 0.977 & 0.506 & 0.986 & 0.593 \\
E & 67.8 & 0.467 & 0.982 & 0.487 & 1.021 & 0.499 \\
F & 71.8 & 0.517 & 0.980 & 0.507 & 1.014 & 0.498 \\
G & 77.9 & 0.566 & 0.979 & 0.566 & 0.989 & 0.514 \\
\hline
\end{tabular}

$C_{p}=0.004184 \mathrm{MJ} / \mathrm{kg}^{\circ} \mathrm{C} ; b=$ dimensionless. 
Table 3. Test results for 31 commercially available solar systems

\begin{tabular}{|c|c|c|c|c|c|c|c|}
\hline $\begin{array}{l}\text { System } \\
\text { no. }\end{array}$ & $\begin{array}{c}\mathrm{M} \\
(\mathrm{kg})\end{array}$ & $\begin{array}{c}A_{c} \\
\left(\mathrm{~m}^{2}\right) \\
\end{array}$ & $\begin{array}{r}M / A_{c} \\
\left(\mathrm{~kg} / \mathrm{m}^{2}\right) \\
\end{array}$ & $\alpha_{o}$ & $\begin{array}{c}U_{s} \\
\left(\mathrm{MJ} / \mathrm{m}^{2}{ }^{\circ} \mathrm{C} \text { day }\right)\end{array}$ & $\eta^{*}$ & $\begin{array}{c}\tau_{c} \\
(\text { day }) \\
\end{array}$ \\
\hline 1 & 272.35 & 3.71 & 73.51 & $0.406 \pm 0.029$ & $0.153 \pm 0.035$ & 0.41 & 2.46 \\
\hline 2 & 290.03 & 3.69 & 78.69 & $0.514 \pm 0.009$ & $0.140 \pm 0.010$ & 0.51 & 3.32 \\
\hline 3 & 283.23 & 3.80 & 74.49 & $0.585 \pm 0.016$ & $0.158 \pm 0.019$ & 0.59 & 2.33 \\
\hline 4 & 305.76 & 3.74 & 81.66 & $0.510 \pm 0.017$ & $0.136 \pm 0.021$ & 0.50 & 2.61 \\
\hline 5 & 254.32 & 3.75 & 67.75 & $0.488 \pm 0.016$ & $0.126 \pm 0.025$ & 0.50 & 2.81 \\
\hline 6 & 201.63 & 2.81 & 71.68 & $0.510 \pm 0.009$ & $0.145 \pm 0.012$ & 0.52 & 2.69 \\
\hline 7 & 300.00 & 3.85 & 78.00 & $0.516 \pm 0.008$ & $0.185 \pm 0.020$ & 0.51 & - \\
\hline 8 & 290.00 & 3.61 & 80.30 & $0.470 \pm 0.018$ & $0.191 \pm 0.027$ & 0.46 & 3.21 \\
\hline 9 & 318.60 & 3.97 & 80.20 & $0.541 \pm 0.037$ & $0.187 \pm 0.045$ & 0.53 & 4.00 \\
\hline 10 & 298.00 & 3.68 & 81.00 & $0.575 \pm 0.022$ & $0.171 \pm 0.030$ & 0.56 & 3.00 \\
\hline 11 & 397.70 & 5.52 & 72.00 & $0.519 \pm 0.010$ & $0.163 \pm 0.016$ & 0.52 & 3.50 \\
\hline 12 & 284.00 & 3.74 & 75.90 & $0.571 \pm 0.025$ & $0.142 \pm 0.038$ & 0.57 & 2.97 \\
\hline 13 & 409.30 & 5.62 & 72.80 & $0.562 \pm 0.022$ & $0.159 \pm 0.026$ & 0.57 & 3.20 \\
\hline 14 & 176.30 & 1.87 & 94.30 & $0.574 \pm 0.020$ & $0.156 \pm 0.029$ & 0.55 & 3.82 \\
\hline 15 & 440.10 & 7.49 & 58.80 & $0.508 \pm 0.022$ & $0.114 \pm 0.030$ & 0.53 & 3.26 \\
\hline 16 & 352.20 & 3.68 & 95.70 & $0.550 \pm 0.043$ & $0.167 \pm 0.054$ & 0.52 & 3.43 \\
\hline 17 & 435.40 & 5.52 & 78.90 & $0.546 \pm 0.016$ & $0.109 \pm 0.025$ & 0.54 & 3.27 \\
\hline 18 & 385.10 & 3.68 & 104.60 & $0.599 \pm 0.032$ & $0.179 \pm 0.037$ & 0.55 & 2.21 \\
\hline 19 & 485.50 & 5.52 & 88.00 & $0.535 \pm 0.030$ & $0.153 \pm 0.037$ & 0.52 & 3.47 \\
\hline 20 & 246.80 & 4.29 & 57.54 & $0.425 \pm 0.042$ & $0.136 \pm 0.078$ & 0.45 & 2.40 \\
\hline 21 & 313.60 & 5.71 & 54.90 & $0.420 \pm 0.028$ & $0.117 \pm 0.042$ & 0.44 & 2.80 \\
\hline 22 & 298.80 & 3.79 & 78.90 & $0.555 \pm 0.026$ & $0.158 \pm 0.042$ & 0.55 & 2.46 \\
\hline 23 & 489.00 & 7.37 & 66.40 & $0.463 \pm 0.061$ & $0.132 \pm 0.086$ & 0.47 & 4.39 \\
\hline 24 & 131.30 & 1.80 & 72.95 & $0.461 \pm 0.023$ & $0.156 \pm 0.033$ & 0.46 & 1.02 \\
\hline 25 & 292.70 & 3.63 & 80.60 & $0.476 \pm 0.023$ & $0.131 \pm 0.031$ & 0.47 & 2.71 \\
\hline 26 & 488.50 & 5.44 & 89.80 & $0.510 \pm 0.027$ & $0.127 \pm 0.034$ & 0.50 & 3.82 \\
\hline 27 & 520.00 & 5.44 & 95.60 & $0.557 \pm 0.015$ & $0.136 \pm 0.021$ & 0.53 & 2.99 \\
\hline 28 & 383.70 & 5.53 & 69.40 & $0.539 \pm 0.020$ & $0.207 \pm 0.040$ & 0.55 & 4.79 \\
\hline 29 & 306.70 & 3.69 & 83.10 & $0.517 \pm 0.017$ & $0.126 \pm 0.028$ & 0.51 & 2.91 \\
\hline 30 & 88.85 & 1.29 & 68.85 & $0.497 \pm 0.012$ & $0.177 \pm 0.014$ & 0.51 & 1.52 \\
\hline 31 & 342.1 & 3.63 & 94.30 & $0.571 \pm 0.021$ & $0.166 \pm 0.026$ & 0.55 & 2.08 \\
\hline
\end{tabular}

early 1989 as a necessary condition for the acceptance of the subsidy program. In addition to the performance criterion during energy-collecting periods, $\tau_{c} \geq 2.0$ days will be suggested as an additional criterion for perfor- mance during no-radiation or cooling-loss periods, in order to make the rating more complete.

It is noted that System B presented in Tables 1 and 2, and System No. 2 in Table 3 are of a close-type

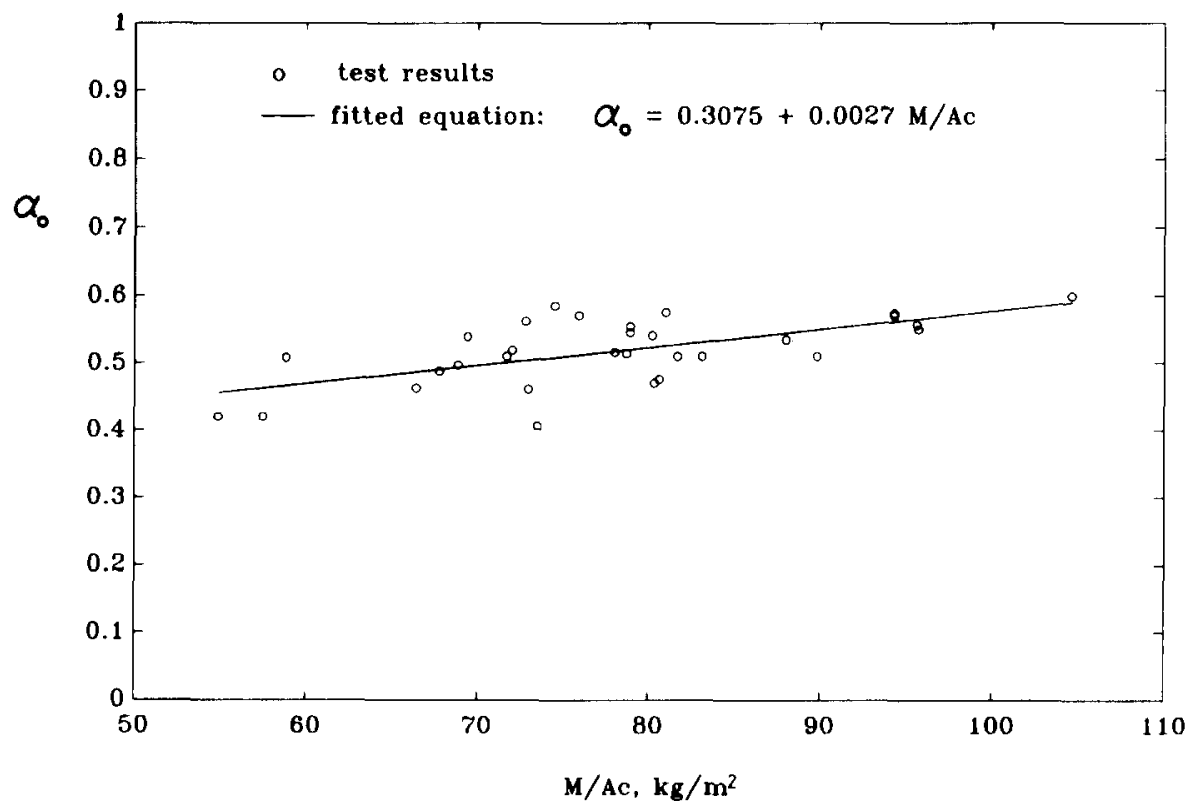

Fig. 1. Variation of $\alpha_{o}$ with $M / A_{c}$. 


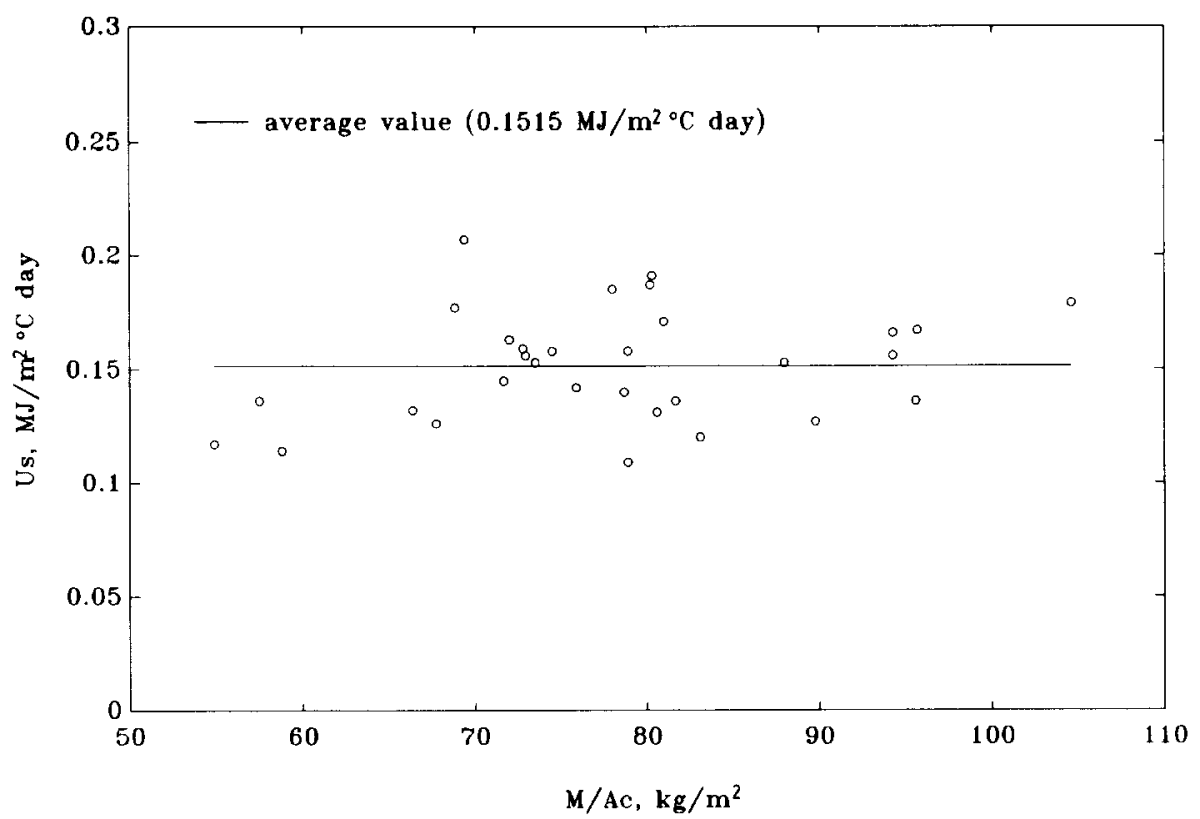

Fig. 2. Variation of $U_{s}$ with $M / A_{c}$.

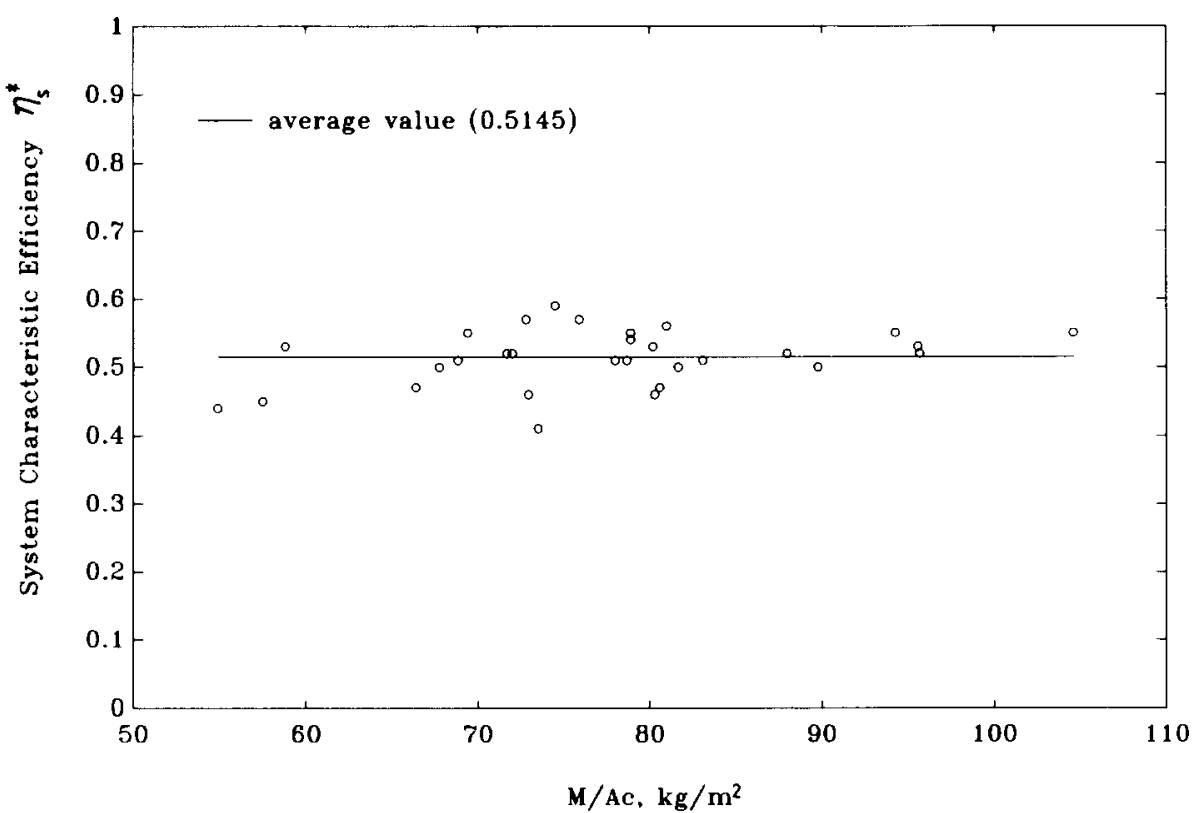

Fig. 3. Variation of $\eta_{s}^{*}$ with $M / A_{c}$.

design (with a heat exchanger in the tank), and no abnormal test results were found. The testing method presented in [1] and Standard CNS B7277[2] are thus shown to be applicable to close-type thermosyphon water heaters with a heat exchanger in the tank. The results obtained from a recent test for a storage-collector type solar water heater (similar to thermosyphonic water heaters in design principle) also reveals that the Standard CNS B7277 is applicable too.

Acknowledgment-This study was supported by the Energy Commission, the Ministry of Economic Affairs, Taiwan, R.O.C., through Grant No. 772J1,782J1,792J6.

\section{NOMENCLATURE}

$A_{c}$ collector area, $\mathrm{m}^{2}$

$b$ empirical constant defined in eqn (3)

$C_{p}$ heat capacity of water, $0.004184 \mathrm{MJ} / \mathrm{kg}{ }^{\circ} \mathrm{C}$

$H_{t}$ daily total solar irradiation upon collector slope, $\mathrm{J} / \mathrm{m}^{2}$ day

$I_{T}$ solar irradiation incident upon collector slope, $\mathrm{W} / \mathrm{m}^{2}$

$M$ total mass of water in the thermosyphon system, $\mathrm{kg}$

$T_{a}$ ambient temperature, ${ }^{\circ} \mathrm{C}$

$\bar{T}_{a}$ daily average ambient temperature, ${ }^{\circ} \mathrm{C}$

$T_{i}$ daily initial tank temperature, ${ }^{\circ} \mathrm{C}$

$T_{f}$ daily final tank temperature, ${ }^{\circ} \mathrm{C}$

$T_{t}$ water temperature in tank, ${ }^{\circ} \mathrm{C}$

$t_{i}$ initial time, $\mathrm{s}$

$t_{f}$ final time, $\mathrm{s}$ 
$U_{s}$ overall system loss coefficient during energy-collecting periods, $\mathrm{MJ} / \mathrm{m}^{2}{ }^{\circ} \mathrm{C}$ day

$(U A)_{L}$ overall system loss coefficient during no-radiation periods, $\mathrm{MJ} / \mathrm{m}^{2}{ }^{\circ} \mathrm{C}$

$\alpha_{e}$ effective solar absorptance, dimensionless

$\alpha_{o}$ overall solar absorptance defined in eqn (1), dimensionless

$\eta_{s}$ daily system efficiency, dimensionless

$\eta_{s}^{*}$ system characteristic efficiency, dimensionless

$\tau_{c}$ cooling time constant during no-radiation periods, day

\section{REFERENCES}

I. B. J. Huang and S. C. Du, A performance test method of solar thermosyphon systems, ASME J Solar Energy Eng. 113, 172-179 (1991).
2. CNS Standard B7277, No. 12558, Method of test for solar water heating systems, Central Bureau of Standard, Ministry of Economic Affairs, Taipei, Taiwan (1989). (in Chinese)

3. R. Kubler, M. Ernst, and N. Fisch, Short term test for solar domestic hot water systems-Experimental results and long term performance predictions, Proceedings of ISES Solar World Congress 1987, September 13-18, 1987, Hamburg, Germany. In: Advances in Solar Energy, Vol. 1, Pergamon Press, Oxford, pp. 732-736 (1988).

4. J. Adnot, B. Bourges, and L. Kadi, The input/output method for SDHWS characterization, Proceedings of ISES Solar World Congress 1987, September 13-18, 1987, Hamburg, Germany. In: Advances in Solar Energy, Vol. 1, Pergamon Press, Oxford, pp. 868-873 (1988). 